\title{
The right ventricle in congenital heart disease - Cardiac T1 mapping for measurements of diffuse myocardial fibrosis
}

\author{
Nadya Al-Wakeel ${ }^{1 *}$, Sarah Nordmeyer ${ }^{1}$, Sevim Yilmaz ${ }^{1}$, Sanaz Rastin ${ }^{1}$, Frédéric H Münch ${ }^{1}$, Felix Berger ${ }^{1}$, \\ Titus Kuehne', Daniel Messroghli \\ From 19th Annual SCMR Scientific Sessions \\ Los Angeles, CA, USA. 27-30 January 2016
}

\section{Background}

Measurements of myocardial extracellular volume (ECV) through cardiac magnetic resonance (CMR) based T1 mapping allow for non-invasive quantification of diffuse myocardial fibrosis. The evaluation of the right ventricle (RV), often mainly affected in congenital heart disease (CHD), is complicated by its typical morphologic characteristics - a thin myocardium and a distinct trabeculation. This study aims to evaluate ECV measurements of the RV in patients with CHD and to introduce a tool that simplifies RV ECV analysis.

\section{Methods}

CHD patients ( $\mathrm{n}=47$; mean age $27.9 \pm 9.6$ years) were prospectively enrolled and compared with 17 healthy volunteers (mean age $25.1 \pm 2.7$ years). T1 maps were generated with Modified Look-Locker Inversion recovery (MOLLI) T1 mapping in a single midventricular plane in short axis (SAX) and transverse orientation (TRANS) before and 15 minutes after bolus application of GdDOTA or Gd-DTPA. To measure ECV, T1 values of the anterior or inferior RV wall were used. Regions of interest (ROIs) were evaluated with regard to image quality (1: no artifacts in RV, good contrast between blood and myocardium; 2: minor artifacts, good/sufficient contrast; 3: major artifacts and/or insufficient contrast) and ROI thickness (1: $>2$ pixels; $2: 1-2$ pixels; $3:<1$ pixel). ECV from plane RV ROIs were compared with ECV obtained from a custom-made tool that derives the mean $\mathrm{T} 1$ values from a curved line manually drawn in the center of the myocardial wall ("centerline ECV").

\section{Results}

RV ECV could be determined in 40 patients $(32 \pm 0.05)$ and 9 volunteers $(0.28 \pm 0.03)$ with a strong correlation of ECV values from SAX and TRANS ( $\mathrm{r}=0.91$, and $0.95 ; \mathrm{p}<0.05$, respectively). In both groups average image quality was rated with grade 1 and mean RV ROI thickness with grade 2. ECV could not be measured in cases of insufficient contrast between blood and myocardium or ROI thickness $<1$ pixel. ECV from ROIs and corresponding centerline ECV correlated strongly in SAX and TRANS in CHD patients $(r=0.97$, and 0.92; $\mathrm{p}<0.05$, respectively) and volunteers $(\mathrm{r}=0.91 ; \mathrm{p}<0.05$, respectively).

\section{Conclusions}

1. RV ECV can be assessed with T1 mapping in SAX and TRANS provided that

a) image quality allows for sufficient distinction between blood and myocardium, and

b) RV wall thickness is $>1$ pixel.

2. The application of a simple line centered in the RV myocardium instead of a plane ROI simplifies and accelerates measurements of RV ECV.

Under these conditions, measurements of RV ECV can be integrated into clinical CMR routine across a wide spectrum of CHD.

\section{Authors' details \\ ${ }^{1}$ Congenital Heart Disease / Pediatric Cardiology, Deutsches Herzzentrum Berlin, Berlin, Germany. ²Deutsches Herzzentrum Berlin, Berlin, Germany.}


doi:10.1186/1532-429X-18-S1-O25

Cite this article as: Al-Wakeel et al:: The right ventricle in congenital heart disease - Cardiac T1 mapping for measurements of diffuse myocardial fibrosis. Journal of Cardiovascular Magnetic Resonance 2016 18(Suppl 1):O25.

Submit your next manuscript to BioMed Central and take full advantage of:

- Convenient online submission

- Thorough peer review

- No space constraints or color figure charges

- Immediate publication on acceptance

- Inclusion in PubMed, CAS, Scopus and Google Scholar

- Research which is freely available for redistribution

Submit your manuscript at www.biomedcentral.com/submit

() Biomed Central 